\title{
Preclinical Evaluation of CD40-Directed Immunotherapy in B-Cell Lymphoma Using [18F]Fluorothymidine-PET
}

\author{
Nicolas Graf ${ }^{*}$, Zhoulei Li², Ken Herrmann",3, Michaela Aichler ${ }^{4}$, Jolanta Slawska1, \\ Axel Walch4, Christian Peschel1,5, Markus Schwaiger ${ }^{2,5}$, Andreas K. Buck ${ }^{2,3}$, \\ Tobias Dechow ${ }^{1}$, Ulrich Keller ${ }^{1,5}$ \\ ${ }^{1}$ III. Medical Department of Hematology and Medical Oncology, Technische Universität München, Munich, \\ Germany \\ ${ }^{2}$ Department of Nuclear Medicine, Technische Universität München, Munich, Germany \\ ${ }^{3}$ Department of Nuclear Medicine, Universität Sklinikum Würzburg, Würzburg, Germany \\ ${ }^{4}$ Institute of Pathology-Analytical Pathology, Helmholtz Zentrum München, Neuherberg, Germany \\ ${ }^{5}$ German Cancer Consortium (DKTK) and German Cancer Research Center (DKFZ), Heidelberg, Germany \\ Email: ${ }^{*}$ nicolasgraf@gmx.de
}

Received 5 February 2015; accepted 7 April 2015; published 9 April 2015

Copyright (C) 2015 by authors and Scientific Research Publishing Inc.

This work is licensed under the Creative Commons Attribution International License (CC BY).

http://creativecommons.org/licenses/by/4.0/

cc) (i) Open Access

\section{Abstract}

Background: Inhibition of the lymphoma surface antigen CD40 by the antagonistic CD40 antibody NVP-HCD122 (HCD122) demonstrates activity in various lymphoma subtypes. In this preclinical in vivo study we examined the suitability of positron emission tomography (PET) using the thymidine analogue 3'-deoxy-3'-[18F]fluorothymidine (FLT) for early response assessment upon HCD122 treatment in diffuse large B cell lymphoma (DLBCL). Methods: Immunodeficient mice bearing human DLBCL xenografts (SU-DHL-4) received weekly intraperitoneal injections of HCD122. Tumor growth was followed up until Day 14. Molecular imaging with FLT-PET was performed before (Day 0) and after start of therapy (Day 2 and Day 7). On Day 14 lymphoma xenografts were explanted for immunohistochemical analysis to correlate PET findings with CD40 surface expression on tumor tissue. Results: Treatment with HCD122 significantly delayed tumor growth resulting in a tumor growth inhibition of $45 \%$ on Day 14. Significant reduction of tumor-to-background ratio (TBR) of FLT-PET was seen in treated animals on Day 7 and preceded change of tumor volume, thus predicting therapy response to HCD122. Immunohistochemical analysis of xenografts revealed significantly higher CD40 expression on treated than on untreated tissue. Moreover, we found a significant correlation between CD40 expression and FLT-PET response for xenograft tumor treated with HCD122. Conclusions: Treatment of DLBCL with the antagonistic CD40 antibody HCD122 can

*Corresponding author.

How to cite this paper: Graf, N., et al. (2015) Preclinical Evaluation of CD40-Directed Immunotherapy in B-Cell Lymphoma Using $\left[{ }^{18} \mathrm{~F}\right]$ Fluorothymidine-PET. Advances in Molecular Imaging, 5, 17-28.

http://dx.doi.org/10.4236/ami.2015.52002 
be monitored with FLT-PET as early as seven days after commencement of therapy and seems to increase CD40 expression on tumor tissue.

\author{
Keywords
}

CD40 Antibody, FLT-PET, Lymphoma, Therapy Monitoring

\title{
1. Background
}

The addition of the monoclonal CD20 antibody rituximab to chemotherapy such as CHOP (cyclophosphamide, doxorubicin, vincristine, prednisone) has resulted in significantly higher response rate, prolonged progression free survival and, most importantly, in better overall survival in diffuse large B cell lymphoma (DLBCL) [1]. However, some patients are either refractory to or relapse after rituximab-based therapies which has been, at least in part, attributed to resistance mechanisms to rituximab including overexpression of anti-apoptotic proteins [2] and down-regulation of CD20 expression [3].

The development of therapeutic antibodies targeting other lymphoma surface antigens could therefore improve currently used lymphoma treatment regimens. CD40 is a member of the tumor necrosis factor (TNF) superfamily and is highly expressed on nearly all B-cell malignancies including DLBCL [4]. It is well established that interaction of CD40 with its natural ligand CD40L can rescue tumor cells from apoptosis, prolong survival and augment proliferation [5]-[7]. CD40L is provided either by the microenvironment, i.e. infiltrating T-cells, dendritic cells and mast cells [8] [9], and/or by the tumor itself, i.e. coexpression of CD40 and CD40L on lymphoma cells [10] as well as secretion of biologically active, soluble CD40L [11]. Therefore, disruption of this signaling pathway appears as an attractive strategy in the treatment of B-cell neoplasms. The fully human antiCD40 antagonistic monoclonal antibody NVP-HCD122 (HCD122) has been shown to prevent CD40/CD40L induced activation of signalling pathways, proliferation and survival in primary B-CLL tumor cells. Secondly, HCD122 is a potent mediator of antibody-dependent cellular cytotoxicity (ADCC) [12]. In contrast to rituximab, HCD122 is not internalized upon binding to CD40-positive cells, and does not mediate complement-dependent cytotoxicity (CDC). In a clinical phase I/II study HCD122 demonstrated variable activity in patients with relapsed/refractory lymphoma across various subtypes [13]. The observation of heterogeneity in response to new agents within a particular histology rather than between different entities is in line with other studies in a broad set of hematologic malignancies [14] and underscores the need for predictive markers of early therapy response and resistance, respectively. Such tools would help to circumvent unnecessary toxicity and costs in patients with high probability of treatment failure, and would also support preclinical and clinical evaluation of novel agents.

Positron emission tomography (PET) using the thymidine analogue 3'-deoxy-3'-[ $\left.{ }^{18} \mathrm{~F}\right]$ fluorothymidine (FLT) offers an attractive option for early therapy monitoring. Upon uptake by nucleoside transporters, FLT is phosphorylated by the cytosolic enzyme thymidine kinase 1 (TK1) and is thus trapped within the cell [15]. Due to the close relation between TK1 activity and the S-phase of the cell cycle [16] and further validation of FLT-uptake with the immunohistochemical proliferation marker Ki-67 [17], FLT-PET has been introduced as a reliable surrogate marker for cell proliferation. Regarding different subtypes of aggressive B-cell non-Hodgkin lymphomas (NHL), FLT has proven to be suitable for early response assessment to targeted treatments as well as to classical chemotherapy in both clinical and preclinical studies [18]-[22].

However, the role of FLT-PET in monitoring CD40-directed immunotherapy has not been investigated yet. In this preclinical study we provide evidence that PET imaging with FLT allows early response prediction to immunotherapy with the novel CD40 antibody HCD122 in a DLBCL xenograft mouse model.

\section{Methods}

\subsection{Cell Line and Animal Model}

SU-DHL-4 cells were obtained by the German Collection of Microorganisms and Cell Cultures (DSMZ) and cultured in RPMI 1640 medium containing 10\% fetal bovine serum, $1 \mathrm{mM}$ L-glutamine and 1\% penicilline/ 
streptomycine (Gibco). Expression of CD40 on lymphoma cells was confirmed by flow cyctometry. Six to eight week old female immunodeficient mice (CB-17 SCID) were obtained from Charles River laboratories. Xenografts were generated following subcutaneous injection of $10 \times 10^{6}$ SU-DHL-4 cells suspended in sterile PBS $(100 \mu \mathrm{l})$ into the right shoulder region. All animal experiments were authorized by the regional responsible agency.

\subsection{Antibody and Therapeutic Regimen}

Palpable tumors were detected within 3 to 4 weeks. Measurement of tumor volume was performed with a shifting calliper followed by tumor volume calculation using the formula [length $\left.\times(\text { width })^{2}\right] / 2$. When xenotransplants reached a size of approximately $100 \mathrm{~mm}^{3}$ (Day 0) animals were treated with an intraperitoneal injection of HCD122 (10 mg/kg, provided by Novartis, Basel, Switzerland) solubilized in $5 \%$ glucose solution for in vivo experiments, or glucose (vehicle) only. Treatment was repeated on Day 7.

\subsection{PET Imaging}

FLT was synthesized as previously described [23] and was obtained from the Radiopharmacy Unit of the TU München. Imaging was performed using a micro PET system (Inveon, SIEMENS Preclinical Solutions). FLT was administered via tail vein injection $(100 \mu \mathrm{l})$ at an activity dose of $5-10 \mathrm{MBq}$ per mouse. The accumulation of radiotracer in the tumor was allowed for $60 \mathrm{~min}$. Mice were then imaged for a 15 min static acquisition period.

\subsection{PET Data Analysis}

TBR were calculated to semi-quantitatively assess the tracer accumulation in the tumor. Circular three-dimensional regions of interest (ROI) were placed manually in the area with the highest tumor activity. The diameter was not covering the entire tumor volume to avoid partial volume effects. For determination of background activity, two three-dimensional ROIs were placed in the spinal muscle at the level of the kidneys. Corresponding TBR, mean $_{\text {tumor }} /$ mean $_{\text {muscle }}$ were calculated.

\subsection{Histology and Immunohistochemistry}

Formalin-fixed, paraffin-embedded sections $(3 \mu \mathrm{m})$ of resected tumor tissue were dewaxed, rehydrated and processed according to standard procedures for immunohistochemistry. As primary antibody anti-CD40 (Acris Antibodies, 1:100) diluted in Antibody Diluent (Dako ChemMate) was used. Secondary antibody was DiscoveryTM Universal (Roche, Ventana Tucson, AZ, USA). Signal detection was performed using peroxidase-DAB (diaminobenzidine)-MAP chemistry (Roche, Ventana, Tucson, AZ, USA). Stainings were performed on the automated immunostainer (DISCOVERY XT, Ventana Medical System). To determine CD40 staining intensities all slides were scanned at 20× objective magnification using an Olympus DotSlide scanner. Immunohistochemical staining was quantified with the commercially available image analysis software tool TissueStudio ${ }^{\circledR}$ (Definiens Enterprise Image Intelligence ${ }^{\mathrm{TM}}$ Suite, Definiens AG, Munich, Germany). This software allows for detection and quantification of immunohistochemical staining intensities in different compartments of the cell, i.e. membranes, within a user specified region of interest (ROI). The percentage of cells with non/low, medium and strong specific membrane staining intensity was calculated.

\subsection{Statistical Analysis}

Statistical analyses were performed using the statistical function of Excel 2007 (Microsoft). A p-value $<0.05$ was considered statistically significant as assessed by student's t-test.

\section{Results}

\subsection{Effect of CD40 Inhibition on Tumor Growth in Vivo}

First we investigated the in vivo efficacy of CD40 inhibition with HCD122 in the cell line-based DLBCL model SU-DHL-4 which shows high expression of CD40 and therefore seems to be a suitable cell line for testing 
HCD122. When xenotransplants reached a volume of about $0.1 \mathrm{~cm}^{3}$ mice received weekly injections of either HCD122 (10 mg/kg i.p.) or glucose 5\% and tumor growth was documented until Day 14 (Figure 1). SU-DHL-4 tumors treated with HCD122 showed reduced growth as compared to untreated (vehicle only treated) lymphomas (Figure 2). Growth curves began to differ significantly from each other starting on Day 10 (therapy group, $\mathrm{n}=8$, mean volume in $\mathrm{cm}^{3} \pm \mathrm{SD}: 0.95 \pm 0.44$ vs. control group, $\left.\mathrm{n}=5: 1.62 \pm 0.27 ; \mathrm{p}=0.043\right)$. In summary, a significant tumor growth inhibition (TGI) of 45\% was evident on Day 14 (1.56 \pm 0.45 vs. $2.85 \pm 0.29$; p = 0.016).

\subsection{Assessment of Early Treatment Response with FLT-PET}

Next we tested whether PET imaging using the FLT tracer was suitable for early response assessment. To this end the TBR of FLT-PET before therapy (baseline, PET-1) was determined and defined as 100\%. Follow-up PET scans (PET-2, PET-3) were performed and change of TBR (relative TBR) was calculated. In PET-2 we observed a lower TBR in the anti-CD40 treatment group (Figure 3; $n=8$; mean TBR \pm SD 127\% $\pm 30 \%$ ) as compared to the control group $(n=5$; mean TBR 186\% \pm 83\%). This difference was, however, not statistically significant $(\mathrm{p}=0.109)$. In the follow-up scan performed on Day 7 (PET-3) treatment with HCD122 resulted in a significant lower TBR $(137 \% \pm 46 \%)$ as compared to the control group $(252 \% \pm 103 \%$; $\mathrm{p}=0.034)$. Thus, PET imaging with FLT was suitable to assess response to CD40 inhibition as early as 7 days after treatment initiation. Importantly, FLT-PET assessment preceded the change of tumor volume (Figure 2). Representative PET images are shown in Figure 4.

We also performed routine FDG-PET in a small number of mice at corresponding time points. TBR of FDGPET did not differ significantly between treatment group (Supplemental Figure S1 and Figure S2; $\mathrm{n}=3$; mean $\mathrm{TBR} \pm \mathrm{SD} 104 \% \pm 10 \%)$ and control group $(\mathrm{n}=3$; mean TBR $\pm \mathrm{SD} 113 \% \pm 4 \% ; \mathrm{p}=0.311)$ in PET-2. A trend towards a lower TBR of FDG-PET in treated mice became apparent in PET-3 ( $=3$; mean TBR \pm SD 93\% \pm $10 \%$ ), which, however, did not reach statistical significance (control group; $n=3$; mean TBR \pm SD $149 \% \pm 24 \%$; $\mathrm{p}=0.061)$.

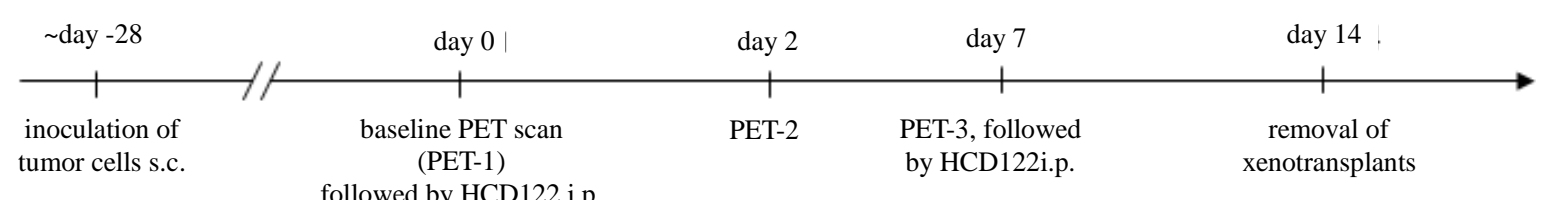

Figure 1. Treatment and PET protocol. Lymphoma cells $\left(10 \times 10^{6}\right.$ SU-DHL-4 cells) were injected subcutaneously into the right shoulder region of SCID mice. When tumour volume reached about $0.1 \mathrm{~cm}^{3}$ mice received static PET imaging (Day 0 , PET-1) followed by HCD122 injection (10 mg/kg i.p.) or glucose 5\%, which was repeated on Day 7. Follow-up PET imaging was performed on Day 2 (PET-2) and Day 7 (PET-3). Finally, lymphoma xenografts were explanted on Day 14 for immunohistochemical analysis.

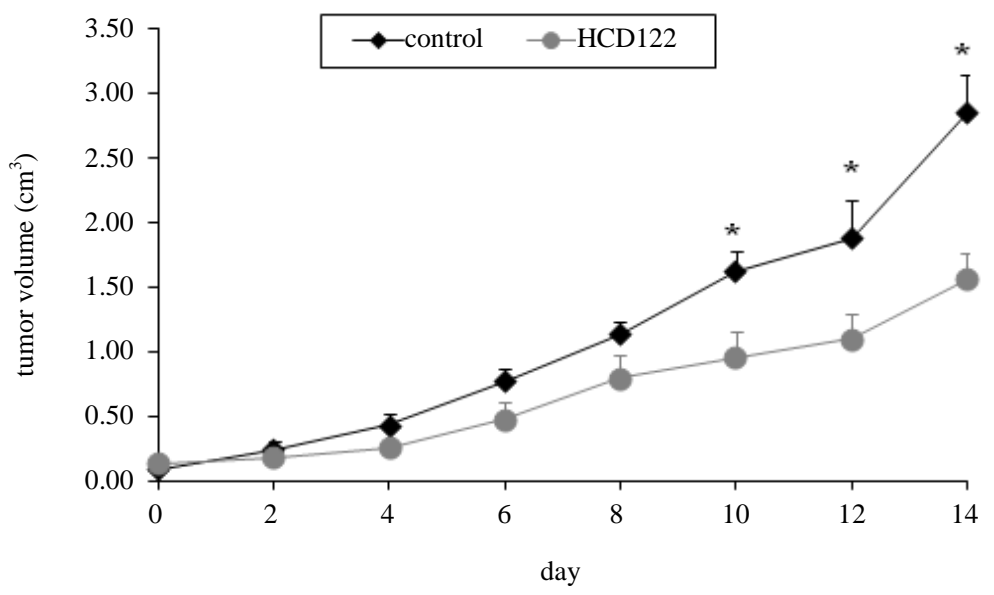

Figure 2. Tumor growth measurements. Mean values $\left(\mathrm{cm}^{3}\right) \pm$ SD of treated (HCD122) and untreated (control) animals are shown. * indicates statistically significant differences at the indicated time points. 


\section{HCD122 a control}

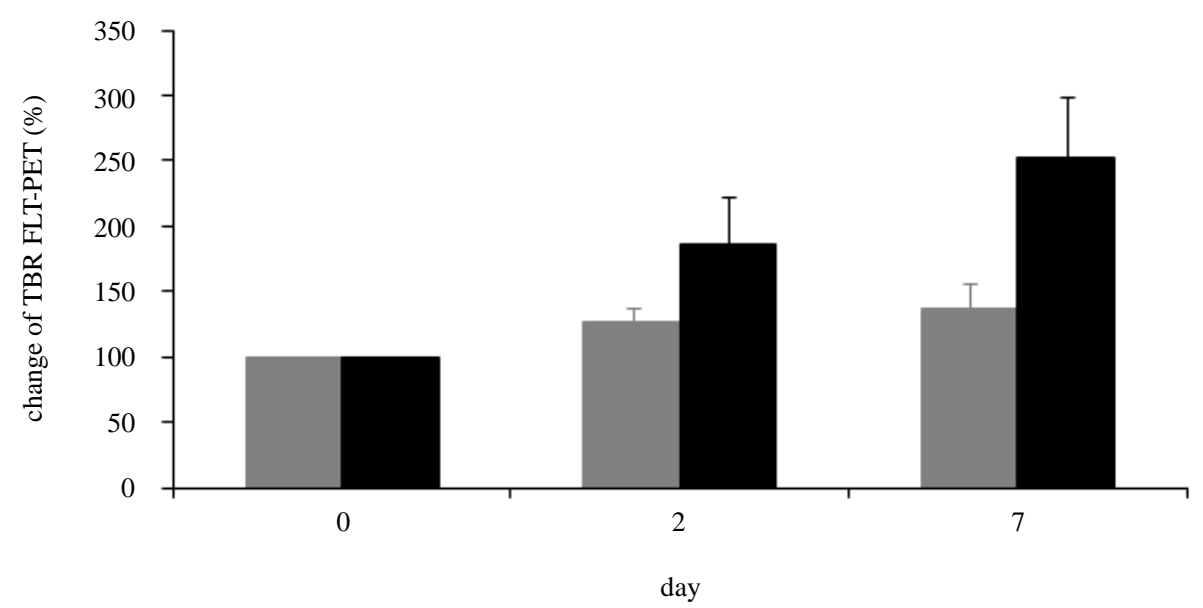

Figure 3. Early assessment of therapy response using FLT-PET. TBR was calculated and served as an indicator of tracer uptake. TBR on Day 0 was defined as $100 \%$. Change of TBR compared to pre-treatment values is shown for treated (HCD122) and control animals. Mean values \pm standard deviation are shown.

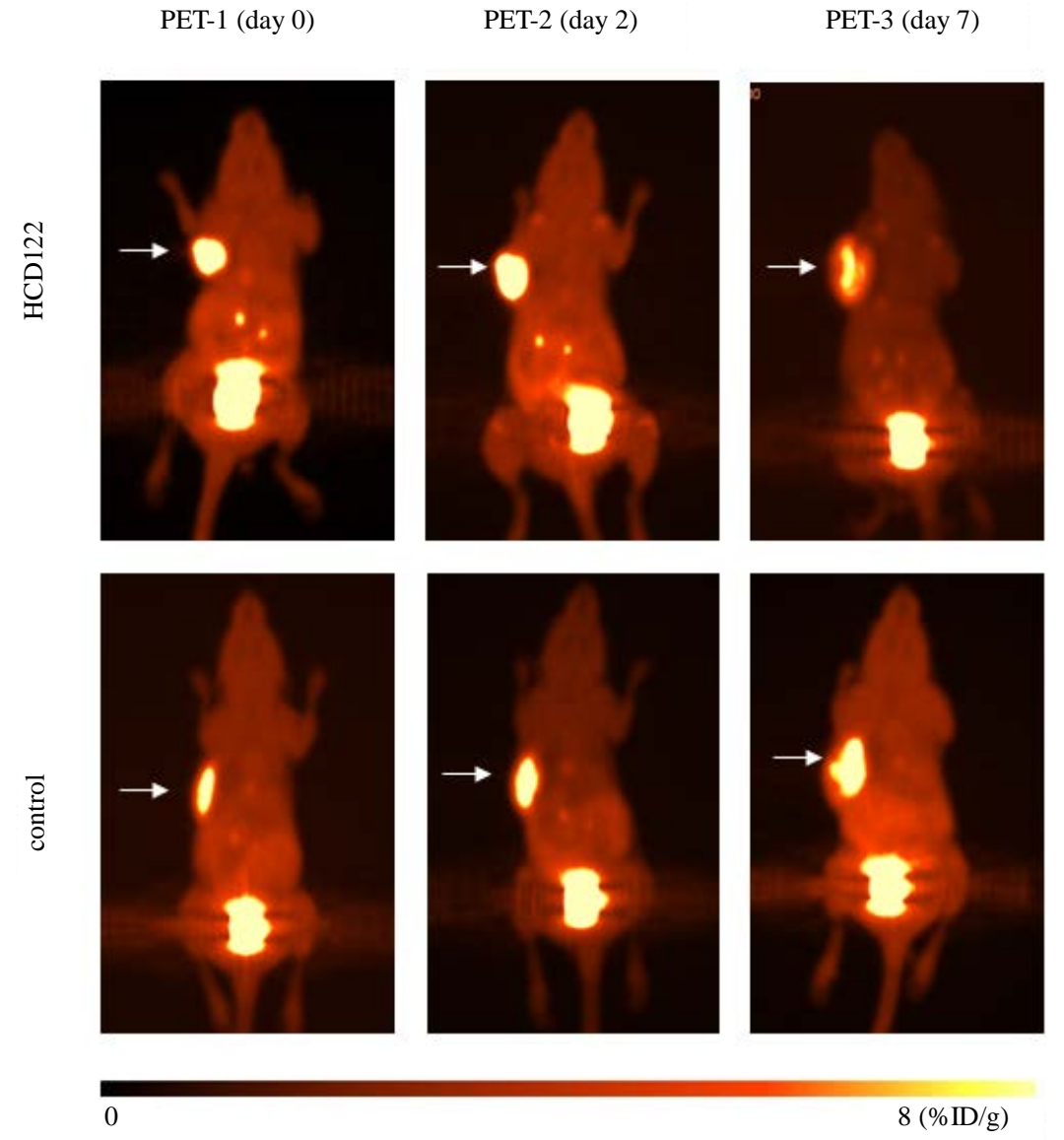

Figure 4. Representative FLT-PET scans showing change of tracer uptake to tumor mass (arrows) in treated (upper panel) and untreated animals (lower panel). Difference of FLTuptake between treated and untreated lymphoma becomes apparent on Day 7. 


\subsection{FLT-PET Results Correlate with High CD40 Expression in Treated Xenograft Lymphomas}

Earlier it has been shown that ADCC activity correlates with the number of antibody target molecules expressed on the cell surface [24]. Based on the assumption that high CD40 expression of lymphoma cells would enhance anti-proliferative effects of HCD122 due to an increased amount of target accessible we explanted xenograft lymphomas on Day 14 for immunohistochemical analysis (treatment group, $n=4$; control group, $n=3$ ). For this purpose the percentage of cells with different levels of CD40 expression was calculated for each section. Interestingly, the percentage of cells with high expression of CD40 (CD40 $\left.{ }^{\mathrm{hi}}\right)$ was significantly higher in treated than in untreated lymphomas (mean \pm SD $92 \% \pm 6 \%$ vs. $31 \% \pm 16 \%, p=0.001$ ). On the contrary, medium or low/ negative CD40 expression was predominantly seen in untreated lymphomas (Figure 5). The heterogeneity of CD40 expression within each lymphoma tissue is outlined in Table 1.

In a second step we explored whether high CD40 expression contributed to antitumor response as reflected by FLT-PET. Therefore, change of TBR on Day 7 was correlated with the percentage of CD40 $0^{\text {hi }}$ cells in the corresponding sections. As shown in Figure 6 there was a strong, negative correlation between these two parameters $\left(\mathrm{R}^{2}=0.908 ; \mathrm{p}=0.047\right)$. Thus, treatment with HCD122 seems to increase CD40 expression in the tumor tissue which in turn leads to attenuated proliferative capacity as depicted by FLT-PET.

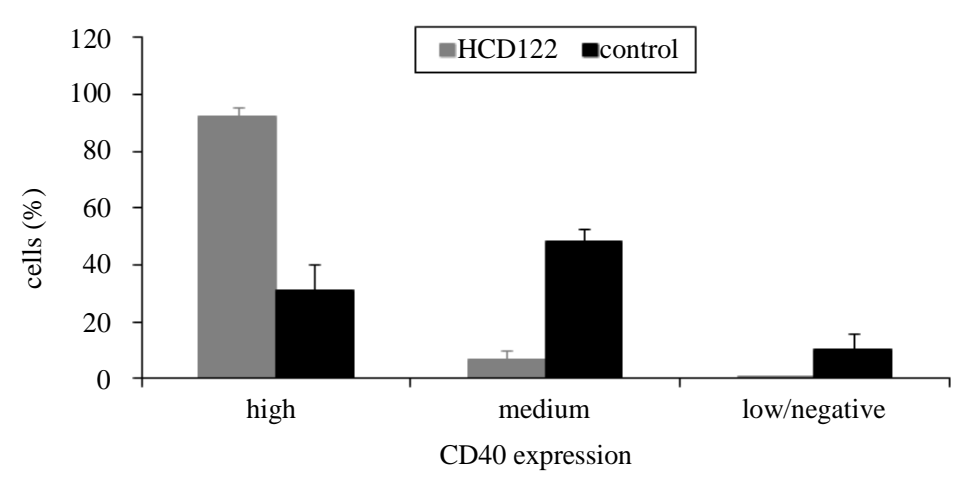

(a)

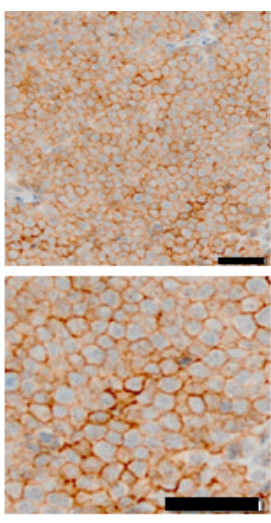

CD40 high

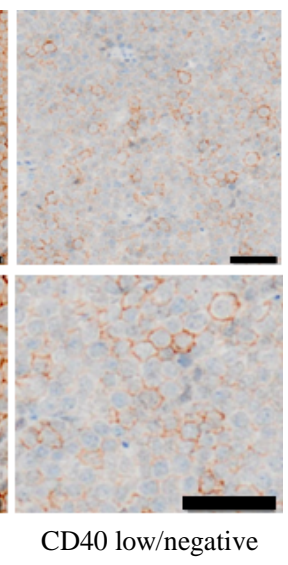

(b)

Figure 5. CD40 expression of explanted xenografts. Left: Xenografts were removed on Day 14 and stained using an antiCD40 antibody (treatment group, $n=4$; control group, $n=3$ ). Staining intensity of each xenograft was assigned to three different levels of CD40 expression (high, medium and low/negative). Histograms indicate mean values, error bars indicate standard deviation. Right: representative slides of lymphoma tissue treated by HCD122 with high and low/negative CD40 expression, respectively. The bars indicate $50 \mu \mathrm{m}$.

Table 1. Heterogeneity of CD40 expression (\%) in each lymphoma tissue. Treatment group ( $\mathrm{n}=4$, listed as HCD no 1 - 4), control group ( $\mathrm{n}=3$, listed as Control no 1 - 3).

\begin{tabular}{|c|c|c|c|c|}
\hline & CD40 high & CD40 medium & CD40 low & CD 40 negative \\
\hline HCD no 1 & 96 & 3 & 0 & 1 \\
\hline HCD no 2 & 83 & 16 & 1 & 1 \\
\hline HCD no 3 & 96 & 3 & 0 & 0 \\
\hline HCD no 4 & 94 & 5 & 0 & 1 \\
\hline Control no 1 & 12 & 42 & 36 & 10 \\
\hline Control no 2 & 36 & 57 & 5 & 1 \\
\hline Control no 3 & 44 & 46 & 9 & 1 \\
\hline
\end{tabular}




\section{Discussion}

The increasing understanding of lymphoma pathogenesis and lymphoma biology has led to the development of multiple monoclonal antibodies targeting lymphoma surface antigens, e.g. CD20, CD22, CD30, CD52 and CD40, which have already been introduced into the clinical routine or are currently tested as unconjugated antibodies, antibody drug conjugates or within radioimmunotherapy approaches [25]. One of the aforementioned approaches is the inhibition of the CD40/CD40L interaction as this pathway provides a growth and survival signal for neoplastic B cells [5]-[11]. An ex vivo study using primary B-CLL cells showed that the anti-CD40 antibody HCD122 exerts antitumor activity by mediating ADCC and inhibiting CD40L-induced survival, proliferation and secretion of cytokines that are implicated in tumor growth [12]. Based on the considerable amount of genetic diversity represented in the group of NHL it is unlikely that inhibition of one single pathway, either by antibody-based or by small molecule inhibitor-based therapy will effectively treat all subtypes of NHL. As a consequence, new substances tend to show a substantial variability in response both within a single and between different lymphoma entities [13] [14]. Hence predictive early biomarkers of response to novel agents are of great interest in the clinical as well as preclinical setting. One option is molecular imaging with PET which allows non-invasive, repetitive, biochemical characterization of the whole organism in vivo.

Basically there are three concepts of imaging immune responses with PET. The first approach uses antibodies or antibody fragments against cell-surface antigens as molecular imaging probes thus allowing cell-surface targets to be profiled in real patients in vivo, i.e. immunohistochemistry in vivo (immunoPET) [26]. However, broad implementation of immunoPET with intact antibodies for early therapy assessment has been hindered by the need to inject tracers several days before imaging. The second approach aims for tracking effector cell localization and function, i.e. mainly T cells, in vivo [27]. In melanoma patients receiving dendritic cell vaccine therapy de novo immune responses mediated by CD4+ and CD8+ T-cells were visualized in treated lymph nodes with FLT-PET, but not with FDG-PET, as early as three days after vaccination [28]. In contrast, murineimmune cells analysed in a preclinical model of immunogenic sarcoma showed distinct patterns of tracer accumulation: FDG accumulated to highest levels in innate immune cells, while activated T cells, though being active for thymidine uptake, appeared unable to retain FLT [29]. Instead, the pyrimidine analogue $\left[{ }^{18}\right.$ F]-2-fluoroarabinofuranosyl-cytosine (FAC) accumulated predominately in CD8+ T-cells in lymphatic tissues in a manner that correlated with cellular proliferation. Importantly, neither FDG nor FAC could efficiently label tumor-infiltrating immune cells. Based on these results and the utilization of T-cell lacking SCID mice [30] in our lymphoma

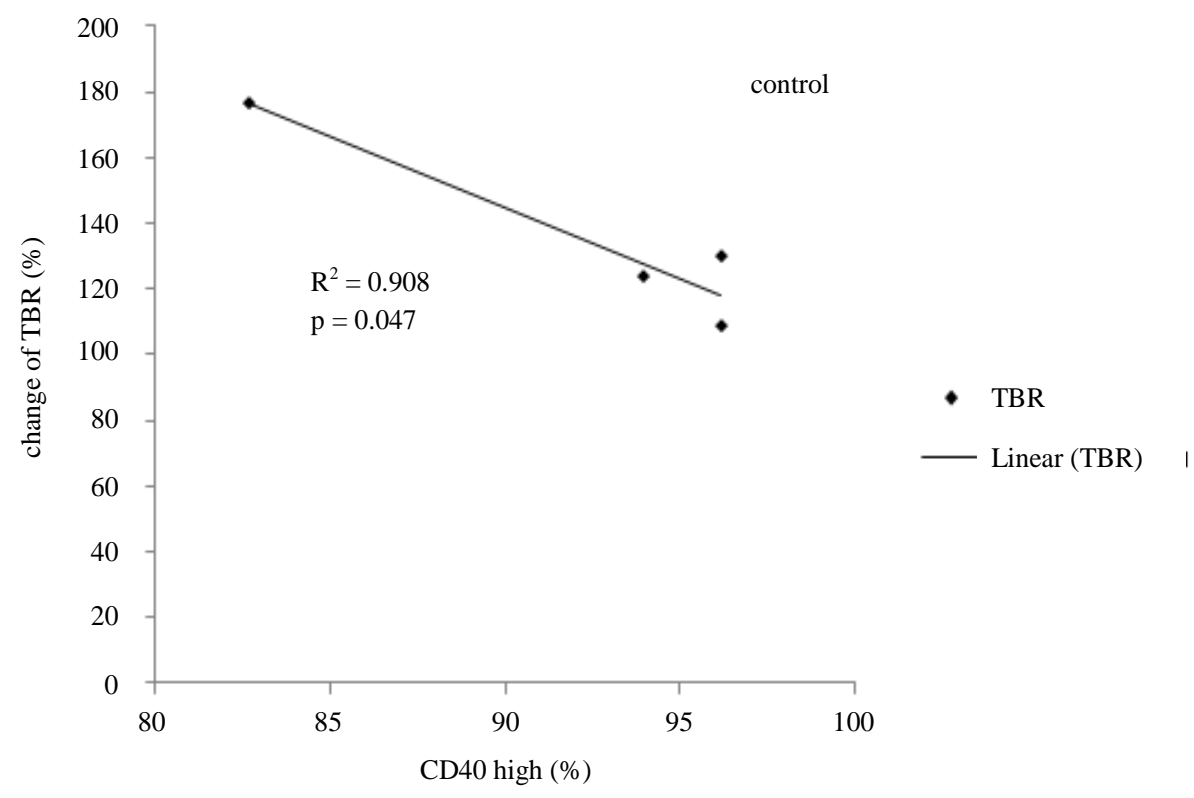

Figure 6. Correlation between high CD40 expression and change of TBR of FLT-PET. The percentage of cells with high CD40 expression in each treated lymphoma $(n=4)$ are plotted against corresponding change of TBR of FLT-PET of the same animal. Regression analysis reveals a strong, negative correlation between these two parameters. 
model, the method of imaging effector cells seemed less constructive for therapy assessment of HCD122. We therefore chose the third approach of imaging immunotherapy, namely the visualization of functional effects on the tumor cell itself. In contrast to the standard tracer FDG, which tracks glucose metabolism, the thymidine analogue FLT reflects cell proliferation, a hallmarks of most cancers [31]. FLT has therefore been widely investigated with respect to cancer detection, staging and therapy response in solid and hematologic malignancies including aggressive lymphomas [18]-[22] [32]. Our experiments provide the first study showing the ability of FLT-PET to predict response to an antagonistic CD40 antibody as early as one week after initiation of therapy.

Early response assessment of monoclonal antibody directed immunotherapy with FLT- and FDG-PET has been investigated mainly in solid tumors. In two studies investigating the monoclonal anti-HER2 antibody trastuzumab in HER2-overexpressing breast cancer xenografts, FLT-PET provided early response assessment following just one week of therapy [33] [34], whereas FDG-PET was unaffected. However, FLT-PET failed to predict response to trastuzumab in a syngeneic breast cancer model [33]. In addition, FLT-PET but not FDG-PET could detect tumor response to anti-epidermal growth factor receptor (EGFR) therapy with cetuximab within three to seven days in preclinical lung [35] and head and neck cancer models [36]. In contrast, cetuximab exerted mainly apoptotic effects without relevant antiproliferative activity in a preclinical colorectal cancer model [37] and thus to no significant difference FLT uptake. Finally, very early FLT-PET one week after CHOP chemotherapy in combination with the CD20 antibody rituximab in DLBCL patients has been shown to identify patients at risk for treatment failure [38], whereas no reduction of FLT-uptake could be observed 48 hours after application of rituximab alone [18]. Selection criteria and timing of PET imaging for the appropriate imaging biomarker seems to be highly dependent on the underlying tumor cell biology and the therapeutic target modulation by the antibody used. Of note, the lack of T cells in our SCID mouse model impairs ADCC since immune cell function is diminished by one highly important component. Therefore, the therapeutic potential of HCD122 is probably underestimated in this setting. As a consequence, the predictive ability of FLT-PET regarding early therapy response assessment could be even more pronounced in clinical studies.

Immunohistochemical analysis of explanted lymphomas revealed a significantly higher expression of CD40 on treated as compared to untreated tumor tissue. Moreover, antiproliferative activity of HCD122 as measured by reduction of FLT uptake correlated with CD40 expression on lymphoma cells. The primary anti-CD40 antibody used for immunohistochemistry stains both human and murine CD40 [39] which offers two different possible sources of the CD40: human lymphoma cells and murine stromal cells. One explanation could be that HCD122, in contrast to rituximab, remains on the surface of lymphoma cells upon binding to CD40 and is not internalized. Its uniform distribution thus provides better conditions for interaction with NK and other effector cells [12]. On the other hand, dendritic and endothelial cells as well as macrophages up-regulate CD40 after uptake of apoptotic bodies and upon stimulation by interleukin-1 by NK cells [40] [41], which could also contribute to the increased CD40 staining in explanted xenografts. So far, there is no clinical data of HCD122 addressing this issue. However, in a phase I trial of the agonistic CD40-antibody dacetuzumab (SGN-40) in patients with relapsed/refractory DLBCL the higher level of CD40 did not correlate with efficacy [42]. Thus, the role of variable CD40 expression on tumor tissue under therapy with HCD122 remains to be determined.

\section{Conclusion}

In summary we show that efficacy of antagonistic CD40-directed immunotherapy can be monitored with FLTPET as soon as 7 days after start of treatment. Our results therefore contribute to the design of clinical studies incorporating FLT-PET imaging into therapeutic protocols containing monoclonal CD40 or further antibodies.

\section{Competing Interests}

The authors declare that there is no conflict of interests.

\section{Acknowledgements}

This work was supported by the Deutsche Forschungsgemeinschaft (SFB 824), the German Cancer Consortium (DKTK) and the German Cancer Research Center (DKFZ). We appreciate the excellent contributions made by our colleague Petra Watzlowik PhD and the great support by our staff members Alexander Hildebrandt, Sybille Reder, Coletta Kruschke and Brigitte Dzewas. 


\section{References}

[1] Coiffier, B., Lepage, E., Briere, J., Herbrecht, R., Tilly, H., Bouabdallah, R., Morel, P., Van Den Neste, E., Salles, G., Gaulard, P., Reyes, F., Lederlin, P. and Gisselbrecht, C. (2002) CHOP Chemotherapy plus Rituximab Compared with CHOP Alone in Elderly Patients with Diffuse Large-B-Cell Lymphoma. The New England Journal of Medicine, 346, 235-242. http://dx.doi.org/10.1056/NEJMoa011795

[2] Dalle, S., Dupire, S., Brunet-Manquat, S., Reslan, L., Plesa, A. and Dumontet, C. (2009) In Vivo Model of Follicular Lymphoma Resistant to Rituximab. Clinical Cancer Research, 15, 851-857. http://dx.doi.org/10.1158/1078-0432.CCR-08-1685

[3] Hiraga, J., Tomita, A., Sugimoto, T., Shimada, K., Ito, M., Nakamura, S., Kiyoi, H., Kinoshita, T. and Naoe, T. (2009) DownRegulation of CD20 Expression in B-Cell Lymphoma Cells after Treatment with Rituximab-Containing Combination Chemotherapies: Its Prevalence and Clinical Significance. Blood, 113, 4885-4893. http://dx.doi.org/10.1182/blood-2008-08-175208

[4] Planken, E.V., Willemze, R. and Kluin-Nelemans, J.C. (1996) The Role of the CD40 Antigen on Malignant B Cells. Leuk Lymphoma, 22, 229-235. http://dx.doi.org/10.3109/10428199609051753

[5] Johnson, P.W., Watt, S.M., Betts, D.R., Davies, D., Jordan, S., Norton, A.J. and Lister, T.A. (1993) Isolated Follicular Lymphoma Cells Are Resistant to Apoptosis and Can Be Grown in Vitro in the CD40/Stromal Cell System. Blood, 82, 1848-1857.

[6] Ghia, P., Boussiotis, V.A., Schultze, J.L., Cardoso, A.A., Dorfman, D.M., Gribben, J.G., Freedman, A.S. and Nadler, L.M. (1998) Unbalanced Expression of bcl-2 Family Proteins in Follicular Lymphoma: Contribution of CD40 Signaling in Promoting Survival. Blood, 91, 244-251.

[7] Andersen, N.S., Larsen, J.K., Christiansen, J., Pedersen, L.B., Christophersen, N.S., Geisler, C.H. and Jurlander, J. (2000) Soluble CD40 Ligand Induces Selective Proliferation of Lymphoma Cells in Primary Mantle Cell Lymphoma Cell Cultures. Blood, 96, 2219-2225.

[8] Clodi, K., Asgary, Z., Zhao, S., Kliche, K.O., Cabanillas, F., Andreeff, M. and Younes, A. (1998) Coexpression of CD40 and CD40 Ligand in B-Cell Lymphoma Cells. British Journal of Haematology, 103, 270-275. http://dx.doi.org/10.1046/j.1365-2141.1998.01031.X

[9] Tournilhac, O., Santos, D.D., Xu, L., Kutok, J., Tai, Y.T., Le Gouill, S., Catley, L., Hunter, Z., Branagan, A.R., Boyce, J.A., Munshi, N., Anderson, K.C. and Treon, S.P. (2006) Mast Cells in Waldenstrom's Macroglobulinemia Support Lymphoplasmacytic Cell Growth through CD154/CD40 Signaling. Annals of Oncology, 17, 1275-1282. http://dx.doi.org/10.1093/annonc/mdl109

[10] Pham, L.V., Tamayo, A.T., Yoshimura, L.C., Lo, P., Terry, N., Reid, P.S. and Ford, R.J. (2002) A CD40 Signalosome Anchored in Lipid Rafts Leads to Constitutive Activation of NF-KappaB and Autonomous Cell Growth in B Cell Lymphomas. Immunity, 16, 37-50. http://dx.doi.org/10.1016/S1074-7613(01)00258-8

[11] Younes, A., Snell, V., Consoli, U., Clodi, K., Zhao, S., Palmer, J.L., Thomas, E.K., Armitage, R.J. and Andreeff, M. (1998) Elevated Levels of Biologically Active Soluble CD40 Ligand in the Serum of Patients with Chronic Lymphocytic Leukaemia. British Journal of Haematology, 100, 135-141. http://dx.doi.org/10.1046/j.1365-2141.1998.00522.x

[12] Luqman, M., Klabunde, S., Lin, K., Georgakis, G.V., Cherukuri, A., Holash, J., Goldbeck, C., Xu, X., Kadel 3rd, E.E., Lee, S.H., Aukerman, S.L., Jallal, B., Aziz, N., Weng, W.K., Wierda, W., O’Brien, S. and Younes, A. (2008) The Antileukemia Activity of a Human Anti-CD40 Antagonist Antibody, HCD122, on Human Chronic Lymphocytic Leukemia Cells. Blood, 112, 711-720. http://dx.doi.org/10.1182/blood-2007-04-084756

[13] Fanale, M., Assouline, S., Kuruvilla, J., Solal-Céligny, P., Heo, D.S., Verhoef, G., Corradini, P., Abramson, J.S., Offner, F., Engert, A., Dyer, M.J., Carreon, D., Ewald, B., Baeck, J., Younes, A. and Freedman, A.S. (2014) Phase IA/II, Multicentre, Open-Label Study of the CD40 Antagonistic Monoclonal Antibody Lucatumumab in Adult Patients with Advanced Non-Hodgkin or Hodgkin Lymphoma. British Journal of Haematology, 164, 258-265. http://dx.doi.org/10.1111/bjh.12630

[14] Walsh, K., McKinney, M.S., Love, C., Liu, Q., Fan, A., Patel, A., Smith, J., Beaven, A., Jima, D.D. and Dave, S.S. (2013) PAK1 Mediates Resistance to PI3K Inhibition in Lymphomas. Clinical Cancer Research, 19, 1106-1115. http://dx.doi.org/10.1158/1078-0432.CCR-12-1060

[15] Shields, A.F., Grierson, J.R., Dohmen, B.M., Machulla, H.J., Stayanoff, J.C., Lawhorn-Crews, J.M., Obradovich, J.E., Muzik, O. and Mangner, T.J. (1998) Imaging Proliferation in Vivo with [F-18]FLT and Positron Emission Tomography. Nature Medicine, 4, 1334-1336. http://dx.doi.org/10.1038/3337

[16] Rasey, J.S., Grierson, J.R., Wiens, L.W., Kolb, P.D. and Schwartz, J.L. (2002) Validation of FLT Uptake as a Measure of Thymidine Kinase-1 Activity in A549 Carcinoma Cells. Journal of Nuclear Medicine, 43, 1210-1217.

[17] Wagner, M., Seitz, U., Buck, A., Neumaier, B., Schultheiss, S., Bangerter, M., Bommer, M., Leithäuser, F., Wawra, E., Munzert, G. and Reske, S.N. (2003) 3'-[ $\left[{ }^{18}\right.$ F]Fluoro-3'-Deoxythymidine ([$\left.\left.{ }^{18} \mathrm{~F}\right]-\mathrm{FLT}\right)$ as Positron Emission Tomography 
Tracer for Imaging Proliferation in a Murine B-Cell Lymphoma Model and in the Human Disease. Cancer Research, 63, 2681-2687.

[18] Herrmann, K., Wieder, H.A., Buck, A.K., Schöffel, M., Krause, B.J., Fend, F., Schuster, T., zum Büschenfelde, C.M., Wester, H.J., Duyster, J., Peschel, C., Schwaiger, M. and Dechow, T. (2007) Early Response Assessment using 3'-Deoxy-3'-[ ${ }^{18}$ F]Fluorothymidine-Positron Emission Tomography in High-Grade Non-Hodgkin's Lymphoma. Clinical Cancer Research, 13, 3552-3558. http://dx.doi.org/10.1158/1078-0432.CCR-06-3025

[19] Herrmann, K., Buck, A.K., Schuster, T., Rudelius, M., Wester, H.J., Graf, N., Scheuerer, C., Peschel, C., Schwaiger, M., Dechow, T. and Keller, U. (2011) A Pilot Study to Evaluate 3'-Deoxy-3'-18 F-Fluorothymidine PET for Initial and Early Response Imaging in Mantle Cell Lymphoma. Journal of Nuclear Medicine, 52, 1898-1902. http://dx.doi.org/10.2967/jnumed.111.094698

[20] Graf, N., Herrmann, K., den Hollander, J., Fend, F., Schuster, T., Wester, H.J., Senekowitsch-Schmidtke, R., zum Büschenfelde, C.M., Peschel, C., Schwaiger, M., Dechow, T. and Buck, A.K. (2008) Imaging Proliferation to Monitor Early Response of Lymphoma to Cytotoxic Treatment. Molecular Imaging and Biology, 10, 349-355. http://dx.doi.org/10.1007/s11307-008-0162-3

[21] Li, Z., Graf, N., Herrmann, K., Jünger, A., Aichler, M., Feuchtinger, A., Baumgart, A., Walch, A., Peschel, C., Schwaiger, M., Buck, A., Keller, U. and Dechow, T. (2012) FLT-PET Is Superior to FDG-PET for Very Early Response Prediction in NPM-ALK-Positive Lymphoma Treated with Targeted Therapy. Cancer Research, 72, 5014-5024. http://dx.doi.org/10.1158/0008-5472.CAN-12-0635

[22] Graf, N., Herrmann, K., Numberger, B., Zwisler, D., Aichler, M., Feuchtinger, A., Schuster, T., Wester, H.J., Senekowitsch-Schmidtke, R., Peschel, C., Schwaiger, M., Keller, U., Dechow, T. and Buck, A.K. (2013) ${ }^{18}$ F]FLT Is Superior to $\left[{ }^{18} \mathrm{~F}\right] \mathrm{FDG}$ for Predicting Early Response to Antiproliferative Treatment in High-Grade Lymphoma in a Dose-Dependent Manner. European Journal of Nuclear Medicine and Molecular Imaging, 40, 34-43. http://dx.doi.org/10.1007/s00259-012-2255-0

[23] Machulla, H.J., Blocher, A., Kuntzsch, M., Piert, M., Wei, R. and Grierson, J. (2000) Simplified Labeling Approach for Synthesizing 3-Deoxy-3 $\left[{ }^{18} \mathrm{~F}\right]$ Fluorothymidine $\left(\left[{ }^{18} \mathrm{~F}\right] \mathrm{FLT}\right)$. Journal of Radioanalytical and Nuclear Chemistry, 243, 843-846. http://dx.doi.org/10.1023/A:1010684101509

[24] Velders, M.P., van Rhijn, C.M., Oskam, E., Fleuren, G.J., Warnaar, S.O. and Litvinov, S.V. (1998) The Impact of Antigen Density and Antibody Affinity on Antibody-Dependent Cellular Cytotoxicity: Relevance for Immunotherapy of Carcinomas. British Journal of Cancer, 78, 478-483. http://dx.doi.org/10.1038/bjc.1998.518

[25] Cheson, B.D. and Leonard, J.P. (2008) Monoclonal Antibody Therapy for B-Cell Non-Hodgkin's Lymphoma. The New England Journal of Medicine, 359, 613-626. http://dx.doi.org/10.1056/NEJMra0708875

[26] Knowles, S.M. and Wu, A.M. (2012) Advances in Immuno-Positron Emission Tomography: Antibodies for Molecular Imaging in Oncology. Journal of Clinical Oncology, 30, 3884-3892. http://dx.doi.org/10.1200/JCO.2012.42.4887

[27] Akins, E.J. and Dubey, P. (2008) Noninvasive Imaging of Cell-Mediated Therapy for Treatment of Cancer. Journal of Nuclear Medicine, 49, 180S-195S. http://dx.doi.org/10.2967/jnumed.107.045971

[28] Aarntzen, E.H., Srinivas, M., De Wilt, J.H., Jacobs, J.F., Lesterhuis, W.J., Windhorst, A.D., Troost, E.G., Bonenkamp, J.J., van Rossum, M.M., Blokx, W.A., Mus, R.D., Boerman, O.C., Punt, C.J., Figdor, C.G., Oyen, W.J. and de Vries, I.J. (2011) Early Identification of Antigen-Specific Immune Responses in Vivo by [ $\left.{ }^{18} \mathrm{~F}\right]$-Labeled 3'-Fluoro-3'-DeoxyThymidine $\left(\left[{ }^{18} \mathrm{~F}\right] \mathrm{FLT}\right)$ PET Imaging. Proceedings of the National Academy of Sciences of the United States of America, 108, 18396-18399. http://dx.doi.org/10.1073/pnas.1113045108

[29] Nair-Gill, E., Wiltzius, S.M., Wei, X.X., Cheng, D., Riedinger, M., Radu, C.G. and Witte, O.N. (2010) PET Probes for Distinct Metabolic Pathways Have Different Cell Specificities during Immune Responses in Mice. Journal of Clinical Investigation, 120, 2005-2015. http://dx.doi.org/10.1172/JCI41250

[30] Greiner, D.L., Hesselton, R.A. and Shultz, L.D. (1998) SCID Mouse Models of Human Stem Cell Engraftment. Stem Cells, 16, 166-177. http://dx.doi.org/10.1002/stem.160166

[31] Hanahan, D. and Weinberg, R.A. (2011) Hallmarks of Cancer: The Next Generation. Cell, 144, 646-674. http://dx.doi.org/10.1016/j.cell.2011.02.013

[32] Tehrani, O.S. and Shields, A.F. (2013) PET Imaging of Proliferation with Pyrimidines. Journal of Nuclear Medicine, 54, 903-912. http://dx.doi.org/10.2967/jnumed.112.112201

[33] Shah, C., Miller, T.W., Wyatt, S.K., McKinley, E.T., Olivares, M.G., Sanchez, V., Nolting, D.D., Buck, J.R., Zhao, P., Ansari, M.S., Baldwin, R.M., Gore, J.C., Schiff, R., Arteaga, C.L. and Manning, H.C. (2009) Imaging Biomarkers Predict Response to Anti-HER2 (ErbB2) Therapy in Preclinical Models of Breast Cancer. Clinical Cancer Research, 15, 4712-4721. http://dx.doi.org/10.1158/1078-0432.CCR-08-2635

[34] Whisenant, J.G., McIntyre, J.O., Peterson, T.E., Kang, H., Sánchez, V., Manning, H.C., Arteaga, C.L. and Yankeelov, T.E. (2015) Utility of $\left[{ }^{18}\right.$ F]FLT-PET to Assess Treatment Response in Trastuzumab-Resistant and Trastuzumab-Sensitive 
HER2-Overexpressing Human Breast Cancer Xenografts. Molecular Imaging and Biology, 17, 119-128. http://dx.doi.org/10.1007/s11307-014-0770-Z

[35] Takeuchi, S., Zhao, S., Kuge, Y., Zhao, Y., Nishijima, K., Hatano, T., Shimizu, Y., Kinoshita, I., Tamaki, N. and Dosaka-Akita, H. (2011) ${ }^{18}$ F-Fluorothymidine PET/CT as an Early Predictor of Tumor Response to Treatment with Cetuximab in Human Lung Cancer Xenografts. Oncology Reports, 26, 725-730.

[36] Atkinson, D.M., Clarke, M.J., Mladek, A.C., Carlson, B.L., Trump, D.P., Jacobson, M.S., Kemp, B.J., Lowe, V.J. and Sarkaria, J.N. (2008) Using Fluorodeoxythymidine to Monitor Anti-EGFR Inhibitor Therapy in Squamous Cell Carcinoma Xenografts. Head \& Neck, 30, 790-799. http://dx.doi.org/10.1002/hed.20770

[37] Manning, H.C., Merchant, N.B., Foutch, A.C., Virostko, J.M., Wyatt, S.K., Shah, C., McKinley, E.T., Xie, J., Mutic, N.J., Washington, M.K., LaFleur, B., Tantawy, M.N., Peterson, T.E., Ansari, M.S., Baldwin, R.M., Rothenberg, M.L., Bornhop, D.J., Gore, J.C. and Coffey, R.J. (2008) Molecular Imaging of Therapeutic Response to Epidermal Growth Factor Receptor Blockade in Colorectal Cancer. Clinical Cancer Research, 14, 7413-7422. http://dx.doi.org/10.1158/1078-0432.CCR-08-0239

[38] Herrmann, K., Buck, A.K., Schuster, T., Abbrederis, K., Blümel, C., Santi, I., Rudelius, M., Wester, H.J., Peschel, C., Schwaiger, M., Dechow, T. and Keller, U. (2014) Week One FLT-PET Response Predicts Complete Remission to RCHOP and Survival in DLBCL. Oncotarget, 5, 4050-4059.

[39] Manufacture’s Instruction, Acris Antibodies.

[40] Ma, D.Y. and Clark, E.A. (2009) The Role of CD40 and CD154/CD40L in Dendritic Cells. Seminars in Immunology, 21, 265-272. http://dx.doi.org/10.1016/j.smim.2009.05.010

[41] van Kooten, C. and Banchereau, J. (2000) CD40-CD40 Ligand. Journal of Leukocyte Biology, 67, 2-17.

[42] Advani, R., Forero-Torres, A., Furman, R.R., Rosenblatt, J.D., Younes, A., Ren, H., Harrop, K., Whiting, N. and Drachman, J.G. (2009) Phase I Study of the Humanized Anti-CD40 Monoclonal Antibody Dacetuzumab in Refractory or Recurrent Non-Hodgkin's Lymphoma. Journal of Clinical Oncology, 27, 4371-4377. http://dx.doi.org/10.1200/JCO.2008.21.3017

\section{Abbreviations}

ADCC: Antibody Dependent Cellular Cytotoxicity;

CDC: Complement Dependent Cyctotoxicity;

FDG: 2-Deoxy-2-[ ${ }^{18}$ F]fluoro-D-glucose;

FLT: 3'-deoxy-3'-[ ${ }^{18}$ F]fluorothymidine;

PET: Positron Emission Tomography;

ROI: Region of Interest;

TBR: Tumor-to-Background Ratio;

TK1: Thymidine Kinase 1. 


\section{Supplemental}

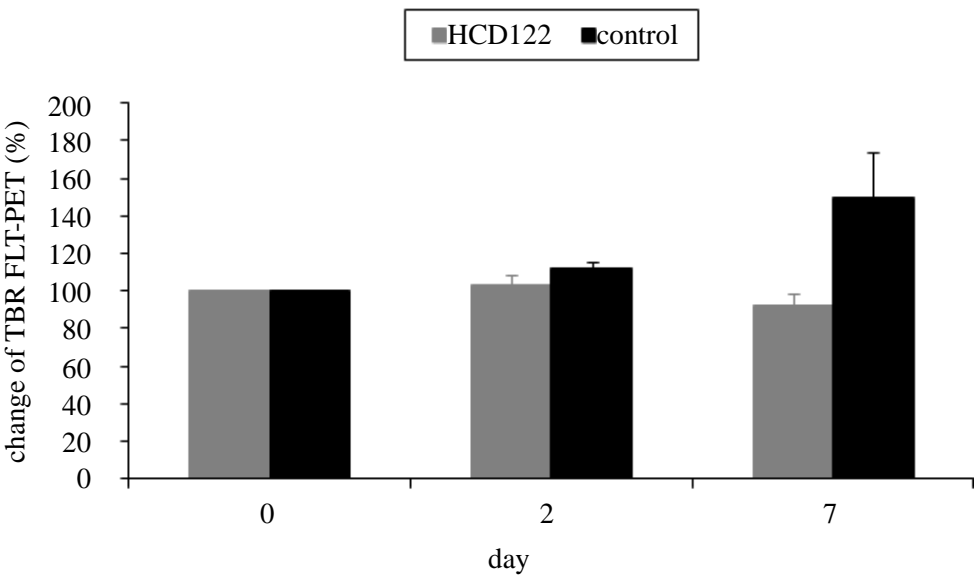

Figure S1. Early assessment of therapy response using FDG-PET. TBR was calculated and served as an indicator of tracer uptake. TBR on Day 0 was defined as $100 \%$. Change of TBR compared to pre-treatment values is shown for treated (HCD122) and control animals. Mean values \pm standard deviation are shown.
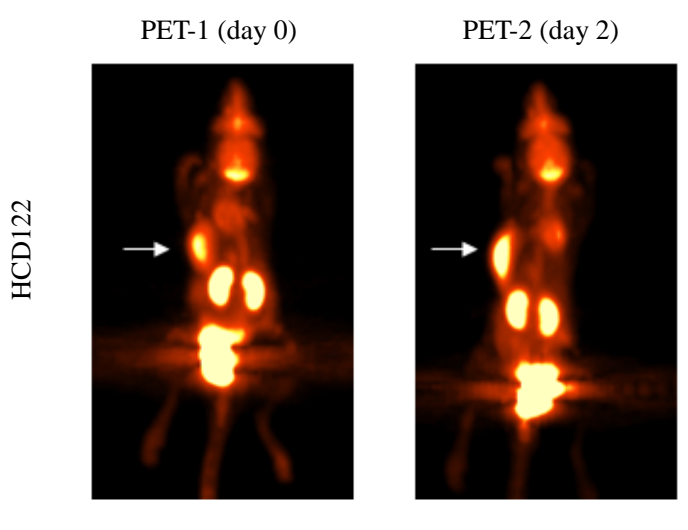

PET-3 (day 7)
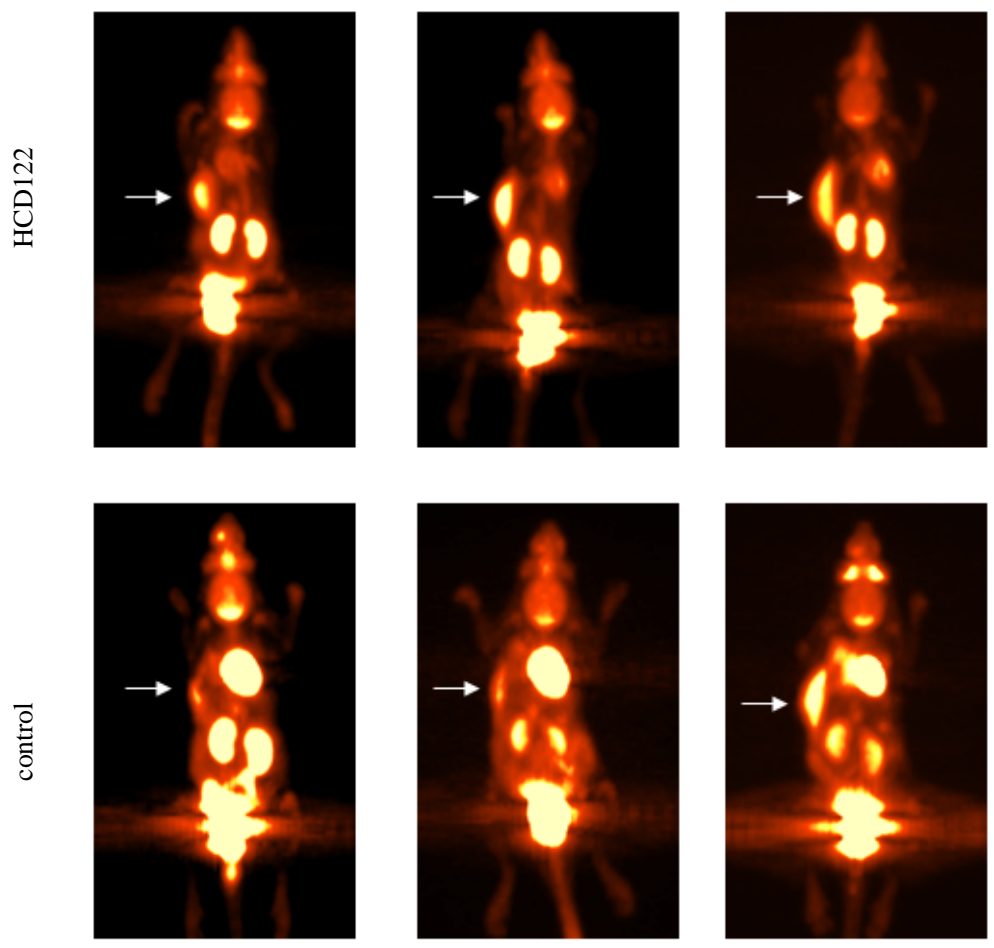

0

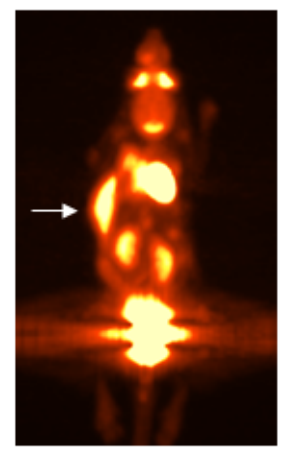

$10(\% \mathrm{ID} / \mathrm{g})$

Figure S2. FDG-PET scans showing change of tracer uptake to tumor mass (arrows) in treated (upper panel) and untreated animals (lower panel). Note, that tumor volume on Day 0 is remarkably smaller in the control than in the treated animal. Therefore visual difference of FDG-uptake on Day 7 does not appear that prominent. 